Textures and Microstructures, Vol. 33, pp. 243-262 Reprints available directly from the publisher Photocopying permitted by license only
(C) 1999 OPA (Overseas Publishers Association) N.V.

Published by license under the Gordon and Breach Science Publishers imprint. Printed in Malaysia.

\title{
RESIDUAL STRESS MEASUREMENTS IN STRUCTURAL COMPONENTS BY NEUTRON DIFFRACTION*
}

\author{
C. OHMS ${ }^{\dagger}$ and A.G. YOUTSOS \\ European Commission, Joint Research Centre, Institute for Advanced \\ Materials, Postbus 2, NL-1755 ZG Petten, The Netherlands
}

\begin{abstract}
Manufacturing processes can generate high residual stress fields that affect the fatigue resistance of components, especially at discontinuities in those that are thick with complex shapes and where radii are small. Welds present residual stress and distortion problems and tremendous challenges for lifetime predictions in aerospace, aero-engine and power generating industries. They represent perhaps $50 \%$ of the problem studies by neutron diffraction but are some of the most difficult to interpret because the composition and structure can vary across the weld and heat-affected zone. The HB4 and HB5 neutron diffraction facilities at the High Flux Reactor (HFR) in Petten have been used for the investigation of residual stresses in two structural component cases. The first concerns an austenitic steel piping weld specimen while the second deals with two low alloy steel cast truck motor part specimens. The overall objective in the second case was the evaluation of the post-production heat treatment process to which one of the two identical specimens was subjected.
\end{abstract}

Keywords: Residual stress; Steel; Neutron diffraction; HFR-Petten

\section{INTRODUCTION}

There is an increasing industrial and academic interest in how residual stresses affect the mechanical properties of materials and fabrications. Failure of a mechanical component or structure is due not only to

\footnotetext{
* This research was carried out within the European Commissions' Research and Development Programme.

${ }^{\dagger}$ Corresponding author.
} 
stresses applied in service but also to the locked-in residual stresses upon which they superimpose. All manufacturing processes introduce some residual stresses. These stresses may be deliberately produced to have a positive effect, such as by peening of critical aerospace components, to increase the fatigue limit by introducing in-plane compressive stresses into surface layers, so as to inhibit the propagation of cracks from surface defects. On the other hand they could have a seriously negative effect, such as to increase stress corrosion cracking rates, if the surface stress field produced by a manufacturing process, such as machining, grinding or welding, happens to be tensile.

Traditionally mechanical, physical and diffraction measurement techniques have been employed. The established mechanical techniques, such as hole drilling or core methods, layer removal and sectioning methods, are all to a greater or lesser extent destructive, as they depend upon the mechanical removal of material, the measurement of the strain relaxation in adjacent areas using surface mounted strain gauges, and the computation of the original stress field from the strain change data.

All these methods are restricted to a few measurements which, being destructive, are not repeatable and subsequent residual stress computations may be uncertain for all but simple shaped samples. Physical techniques using ultrasonic or magnetic techniques have advantages in speed but tend to be very material dependent and only semi-quantitative. Finally the traditional X-ray diffraction method is restricted to surface measurements due to strong absorption of the $\mathrm{X}$-rays in most engineering materials.

Neutron beams are highly penetrating and non-destructive and are used widely in science for studies of condensed matter. In Europe and elsewhere national and international central facilities have been built to service the needs of a wide range of scientists. More recently engineers in collaboration with materials scientists have begun to exploit some of the many uses of neutron beams, in particular to determine residual stresses. The neutron technique, which has been developed over about 15 years at a number of central neutron facilities, is uniquely suited for non-destructively mapping internal residual stress fields in engineering components.

The purpose of this paper is to briefly describe the neutron diffraction facilities at the High Flux Reactor (HFR) in Petten, and to present 
strain-stress results on two structural components based on these facilities.

In Section 2 we describe the HB4 and HB5 neutron diffraction facilities and present results on their performance in relation to residual stress measurements. Concerning the HB4 facility considerable efforts have been made in the last two years in order to upgrade its performance. The progress achieved, in terms of statistical error and sampling time, is shown through results of tests performed on a standard stainless steel specimen.

In Section 3 we present residual strain-stress data measured on a thick austenitic steel piping weld. Measurements in three dimensions were performed both at JRC and CRNL, Canada. It is shown that, based on the upgrading of the HB4/HFR stress diffractometer, it is now possible to map the tensorial stress state within the interior of this weld and the piping heat-affected zone despite the problems of micro-structural inhomogenity and anisotropy due to large grain size and texture exhibited in and around the weld.

In Section 4 we present residual stress data on two specimens representing a low alloy steel cast truck motor part. One of the two specimens was subjected to post-production heat treatment for internal stress relief and this process is evaluated. In fact the test results reveal that the heat treatment process is adequate only in areas close to the surface of the specimen. Finally in Section 5 we discuss the quality of the experimental results and offer a few concluding remarks.

\section{HFR/HB4 AND HB5 NEUTRON DIFFRACTION FACILITIES}

The High Flux Reactor in Petten, The Netherlands, is equipped with 12 horizontal neutron-beam facilities (Frikkee, 1990). Two of them (HB4 and HB5) are designed for the purpose of residual stress measurements by neutron diffraction. HB4 is a dedicated stress diffractometer equipped with a pyrolytic graphite (PG) double monochromator (Brand, 1991). The second diffractometer (HB5) available at the HFR is a two-axes diffractometer employing a $\mathrm{Cu}-111$ monochromator at fixed take-off angles of $33^{\circ}$ or $76^{\circ}$. It can be used for both powder studies and residual stress scanning. 


\section{Description and Performance of $\mathbf{H B 4}$}

HB4 is a dedicated residual stress diffractometer. It has been used for several measurement campaigns in the past (Ezeilo and Webster, 1993; Ohms and Youtsos, 1996; 1997; Schröder and Youtsos, 1994; Youtsos et al., 1994; 1995; 1997; Youtsos and Schröder, 1994. The component that is somewhat unique in this instrument is its double monochromator. It consists of two PG monochromators, which allow for the selection of the required wavelength value from the wavelength range of $1.5-6.5 \AA$. The positioning of the specimen is provided by rotation and translation of the sampling table.

During the past two years considerable efforts have been made to upgrade the facility in order to improve its performance in residual stress measurements. The most important progress has been made by the implementation of a new position-sensitive detector $(\mathrm{Ohms}$ and Timke, 1996a). Figure 1 shows the new instrument setup based on this 32 vertical wire neutron detector. This configuration allows for a $2 \Theta$ scanning over a range of $3.2^{\circ}$ at a fixed detector location yielding a reduction in sampling time of one order of magnitude while the

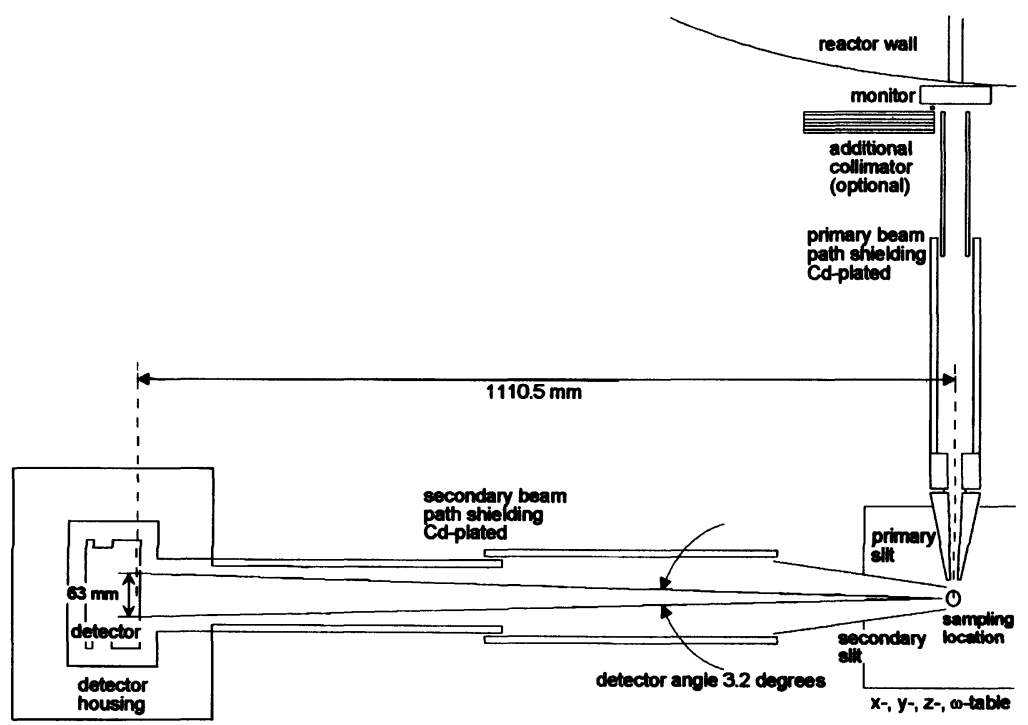

FIGURE 1 New setup of the HB4 stress diffractometer with the multi-wire detector, which enables measurements over 32 points at the same time. 
statistical error level is not increased, as the results shown in Table I clearly demonstrate.

A second measure taken on this facility is the introduction of an advanced beam path shielding shown in Fig. 1. Except for the sampling location itself the neutron path is now entirely covered with $\mathrm{Cd}$ which prevents undesired neutrons from being detected by the multi-wire detector. In addition to this the shielding at the reactor wall at HB4 was upgraded. The effect of these measures was a reduction of background in the relevant $2 \Theta$ range between $60^{\circ}$ and $115^{\circ}$ by almost $50 \%$ (see Fig. 2).

The employment of a PG double monochromator offers several advantages (Ohms and Timke, 1996b). Most important, the possible selection of wavelength in the range of $1.5-6.5 \AA$ allows for the application of a scattering angle of $90^{\circ}$ and consequently a gauge volume of rectangular shape in most cases. Furthermore it gives access to a larger

TABLE I Measurements in a stainless steel block, comparison between the old and the new instrument setup

\begin{tabular}{lcccccc}
\hline Measurement & $2 \Theta$ & $\Delta 2 \Theta$ & $F W H M$ & Area & Gauge volume & Sampling time \\
\hline 11.11 .1995 & 77.131 & 0.013 & 1.67 & 1127 & $3 \times 3 \times 2$ & $43920 \mathrm{~s}$ \\
14.03 .1997 & 77.553 & 0.011 & 1.60 & 1187 & $3 \times 3 \times 2$ & $4800 \mathrm{~s}$ \\
\hline
\end{tabular}

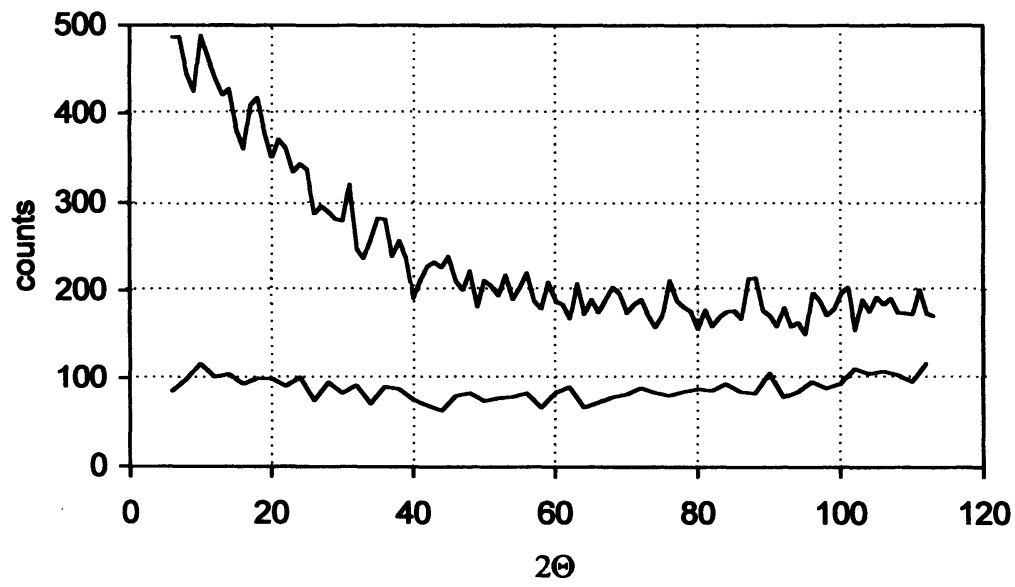

FIGURE 2 Background measurements on HB4, performed in January and March 1997 , showing significant reduction in the background levels. 
selection of reflection planes for cubic materials such as iron or aluminium. A third option available with this installation is the employment of the graphite 004- instead of 002-neutrons. This not only extends the accessible range of wavelengths to $0.75 \AA$, but also improves greatly the instrument resolution.

Data were derived from the 110-reflection of a standard iron powder, which was scanned over a $2 \theta$ range of $3^{\circ}$ by use of the position sensitive detector and are shown in Fig. 3. The peak obtained by use of graphite 002-neutrons exhibits a large intensity but low resolution, and that obtained by use of graphite 004-neutrons offers a low intensity but high resolution. Despite the loss in scattered intensity by at least one order of magnitude the results shown in Table II suggest that the

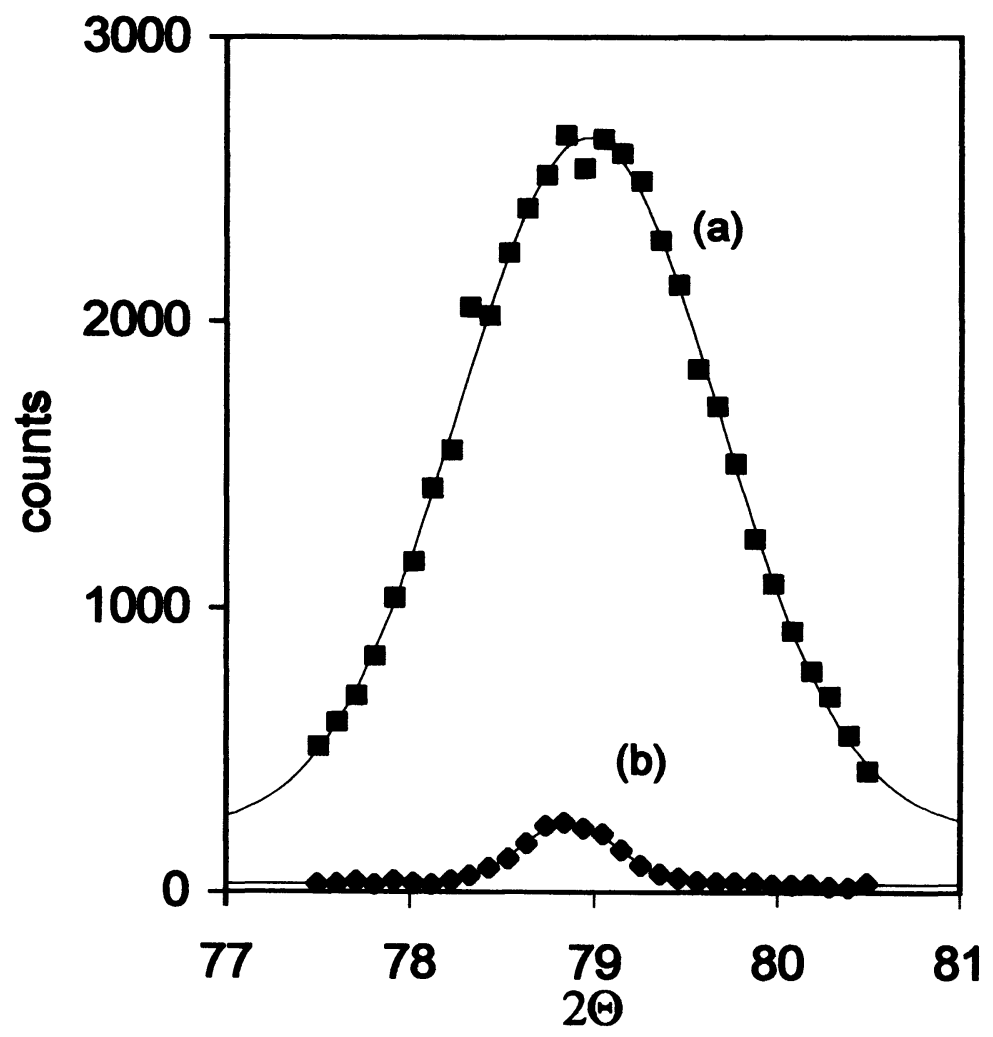

FIGURE 3 Multi-detector and double monochromator performance employing (a) PG 002-neutrons and (b) PG 004-neutrons. 
TABLE II Test results and fitted parameters of multi-detector and PG double monochromator performance

\begin{tabular}{lcccccc}
\hline PG reflection plane & $2 \Theta$ & $\Delta 2 \Theta$ & $F W H M$ & Area & Gauge volume & Sampling time \\
\hline 002 & 78.965 & 0.007 & 1.67 & 4168 & $3 \times 3 \times 31$ & $210 \mathrm{~s}$ \\
004 & 78.862 & 0.005 & 0.61 & 140 & $3 \times 3 \times 31$ & $142 \mathrm{~s}$ \\
\hline
\end{tabular}

quality of the test performed with 004-neutrons is clearly superior even though its duration is considerably shorter. The instrumental resolution could be increased in this case by a factor of ca. 3 .

\section{Description and Performance of $\mathbf{H B 5}$}

HB5 is a double-axis diffractometer with two fixed monochromator take-off angles, i.e. $2 \Theta_{M}=33^{\circ}$ and $76^{\circ}$. It is being used in its standard mode with a $\mathrm{Cu}$ (111) monochromator and $2 \Theta_{M}=76^{\circ}$. This setup produces a monochromatic neutron beam with a wavelength of about $2.572 \AA$. In order to suppress high order contamination of the beam, graphite filters are placed in the beam before and following the monochromator. The detector consists of four single detectors, which allow a range of scattering angle up to $160^{\circ}$. However, for residual stress determination only one detector is used.

The major drawback of HB5 is its fixed take-off angle resulting in a fixed value of the wavelength. This means that for many of the materials to be investigated no strong Bragg reflection exists in the desired $2 \Theta$ range of $75-115^{\circ}$. However, such a reflection plane exists for the most important structural metals ( $\mathrm{Al}, \mathrm{Fe}$, and $\mathrm{Cu}$ ). The high degree of measurement reproducibility exhibited by the HB5 facility is demonstrated by hoop strain data measured on a stainless steel ring round robin (Holden et al., 1992) and shown in Fig. 4. The plotted data compare strains along two radial lines, $1.5 \mathrm{~mm}$ apart, within the specimen plane of symmetry.

\section{RESIDUAL STRESS MEASUREMENT IN AN AUSTENITIC STEEL WELD}

The extent of the improved capabilities of the new setup of the HB4 instrument is further shown by a series of strain measurements 


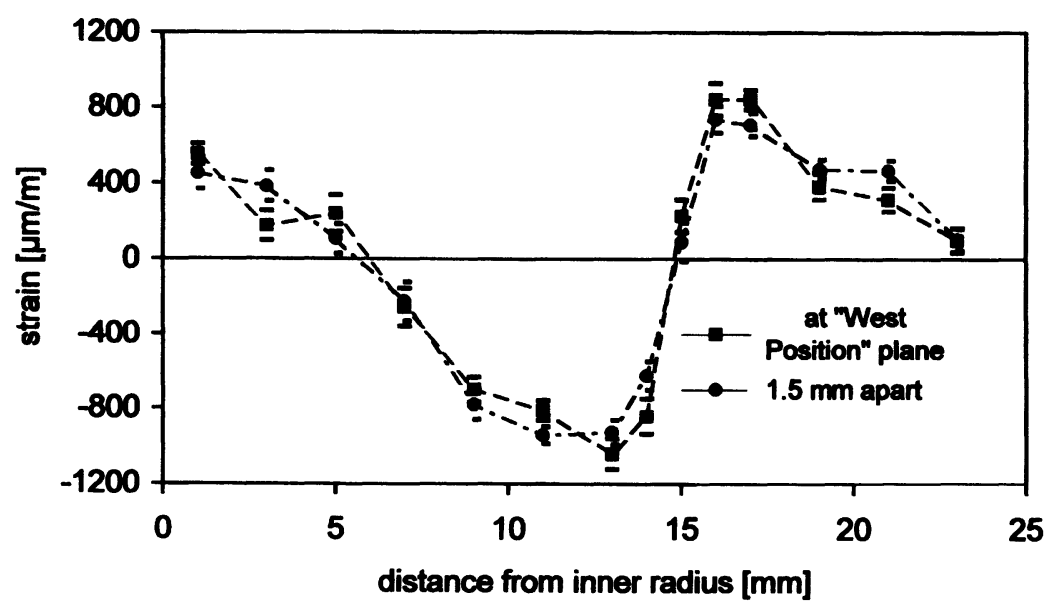

FIGURE 4 Reproducibility of hoop strain measurements performed along two radial lines $-1.5 \mathrm{~mm}$ apart - in an austenitic steel ring round robin.

performed throughout a thick nuclear piping austenitic steel weld. In fact it is shown that it is now possible to map the tensorial stress state within the interior of this weld and the piping heat affected zone despite the problems of micro-structural inhomogenity and anisotropy due to large grain size and texture exhibited in and around the weld.

Concerning welds one has always to be careful about changes in chemistry in the heat-affected zone. This will change the lattice parameter through compositional changes, which can give rise to an apparent strain (Holden, 1996). For this reason one has to take small coupons out of a companion weld and measure the lattice parameter in each of these to obtain the equilibrium lattice parameter as a function of position. Furthermore the lattice parameter must be measured in each direction where strain measurements are desired, within the actual specimen, and based on all reflection planes which are to be used for this purpose. It is assumed that cutting up the weld relieves residual macro-stresses. Any micro-stresses present in the coupons would not be relieved by the cutting operation but it is assumed that they would be identical to any micro-stresses in the welded specimen. Therefore the stress measurements thus determine only the residual macro-stresses in the weld and make no determination of any micro-stresses present (Winholtz and Krawitz, 1995). 
Two measurement campaigns have been performed on a thick nuclear piping austenitic steel butt weld. The first was made at the residual stress diffractometer E3 of Chalk River National Laboratory (CRNL) of Canada, in the context of collaboration between CRNL and JRC, and the second at the HFR-Petten.

Figure 5 shows the location and size of the coupons, which were cut from a companion specimen for the investigation of the macro-stress free lattice parameters. All coupons are 5-mm cubes with their centres at the strain measurement locations.

\section{CRNL Measurement Campaign}

Measurements were made at all locations of the weld transverse direction - line $\mathbf{G}$, which coincides with the piping axial direction, and all locations of the weld axial direction - column 6, which coincides with the piping radial direction. For each of the investigated coupons the lattice parameter was measured using the 113- and 002-reflection planes in the normal, axial and transverse weld directions. The sampling volume chosen for all tests was $3 \times 3 \times 3 \mathrm{~mm}^{3}$ and at a fixed wavelength of $1.528 \AA$ using the Ge-113 neutrons of the monochromator at the E3 neutron beam. This wavelength gives rise to a $2 \Theta$ value near $90^{\circ}$ for the

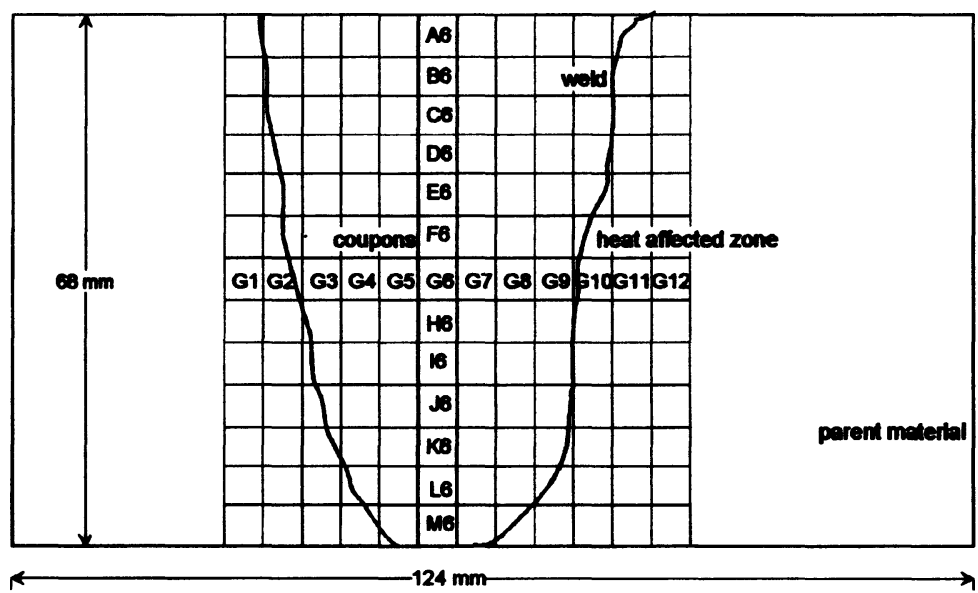

FIGURE 5 Longitudinal cross-section of piping and weld showing measurement locations. 
113-reflection which renders a cubical sampling volume but only $50.4^{\circ}$ for the 002-reflection.

Figures 6 and 7, and Figs. 8 and 9 show the measured diffraction angles in all the coupons examined for the weld axial and normal directions respectively. It can be readily observed that in all cases reported in Figs. 6-9 the $2 \Theta$ values within the weld are much higher

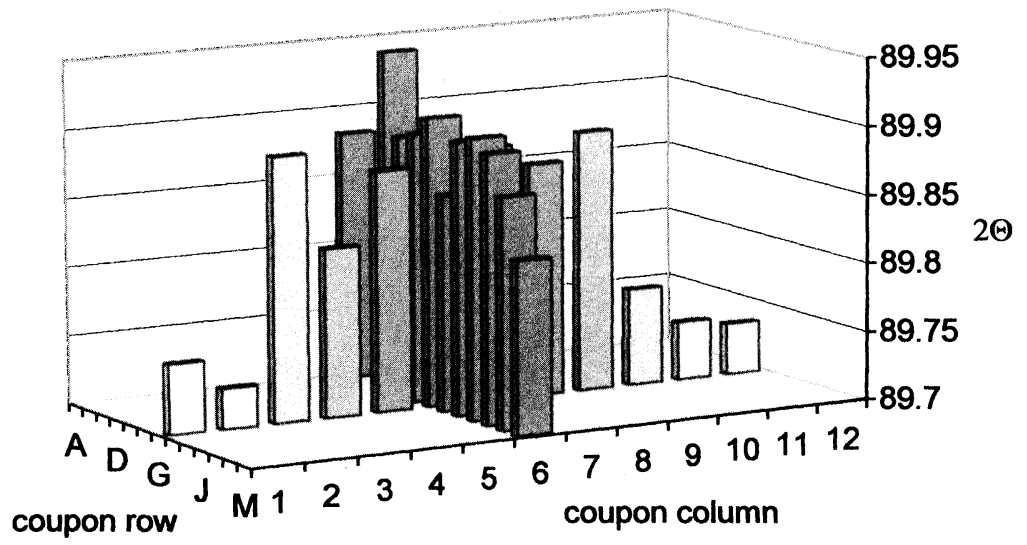

FIGURE 6 Variation of reference diffraction angle for 113-reflection in the weld axial direction.

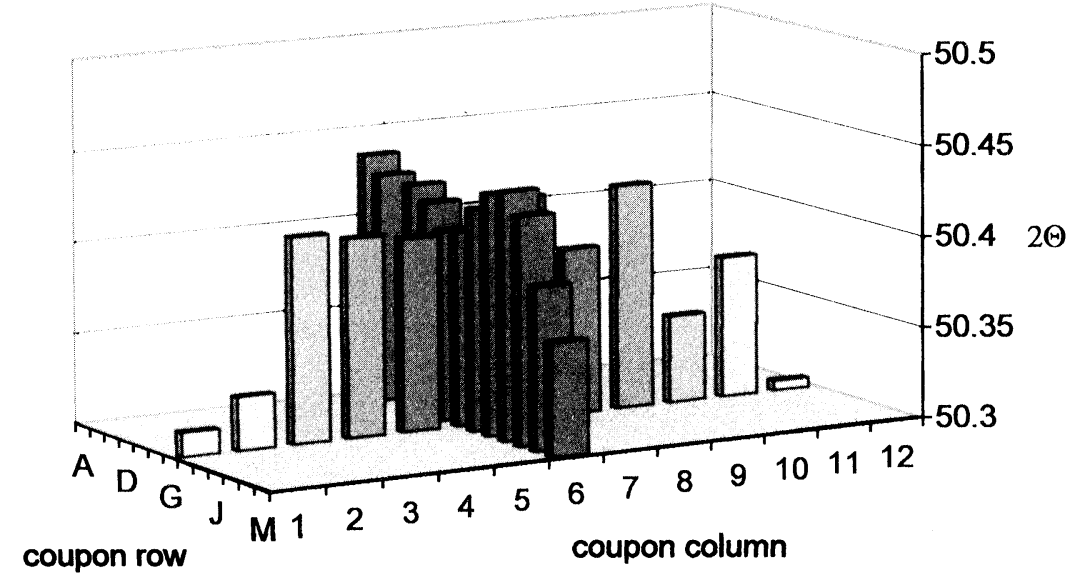

FIGURE 7 Variation of reference diffraction angle for 002-reflection in the weld axial direction. 


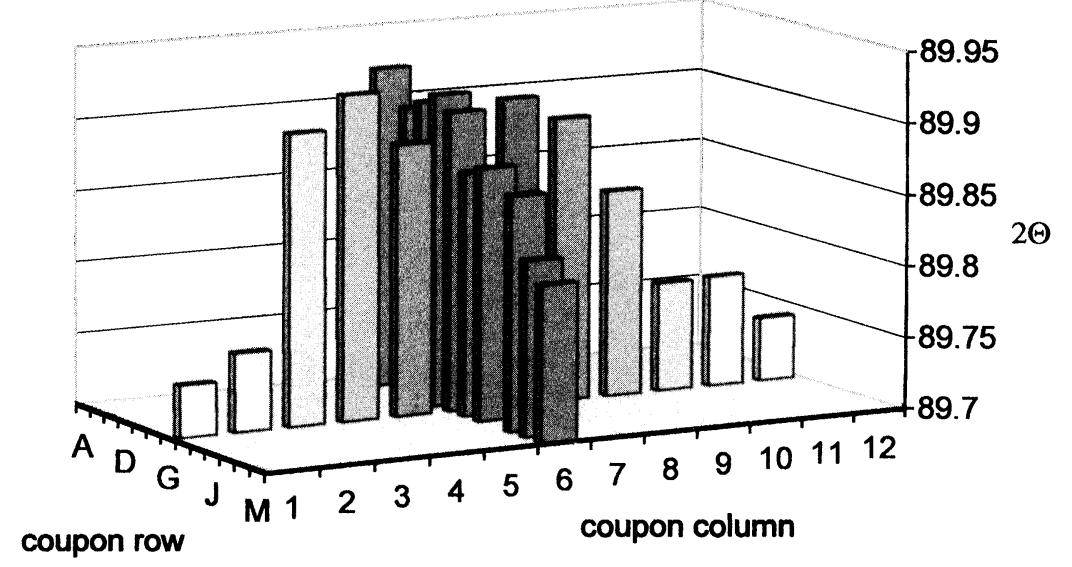

FIGURE 8 Variation of reference diffraction angle for 113-reflection in the weld normal direction.

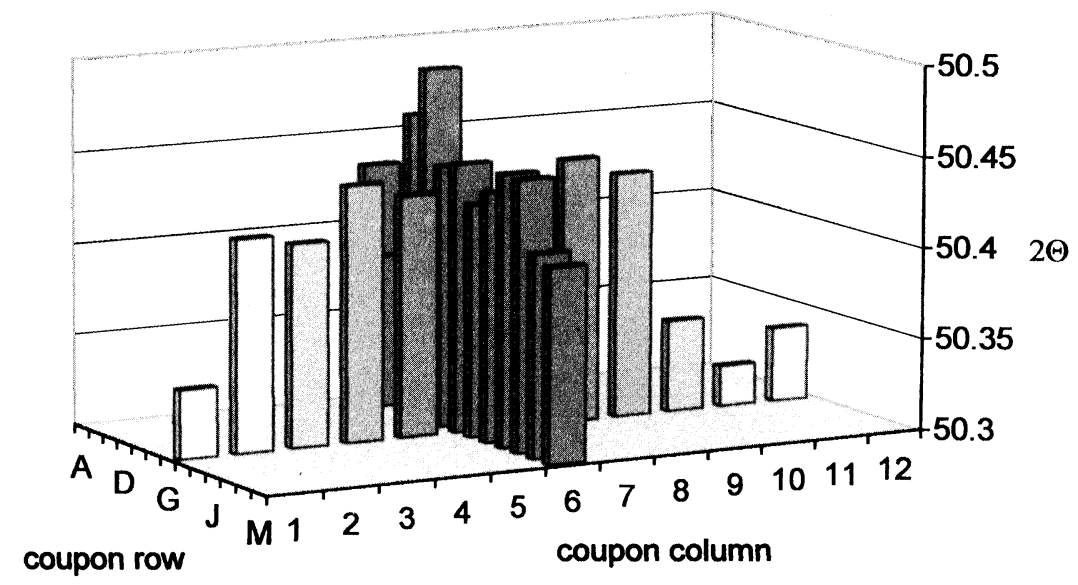

FIGURE 9 Variation of reference diffraction angle for 002-reflection in the weld normal direction.

than in the parent material. In fact for the 113 -reflections $2 \Theta$ varies by as much as $0.25^{\circ}$ and for 002 by about $0.15^{\circ}$ resulting into compressive pseudo-strain levels in the range of 2200 and $2800 \mu \mathrm{m} / \mathrm{m}$ respectively. Strain measurements were made in the weld specimen and in its normal and axial directions using both 002 and 113 . Figure 9 shows the resulting residual strains in the axial direction along the transverse axis of the 
weld based on the 002-reflection and taking correctly into account the macro-stress free lattice parameter variation as shown in Fig. 7. Figure 9 also shows the pseudo-strain data, which one would obtain if this variation were neglected.

Figure 10 suggests that the parent material is undergoing large compressive strains while the strains in the weld are tensile and relatively low. Figure 11 shows strains measured in the weld axial direction

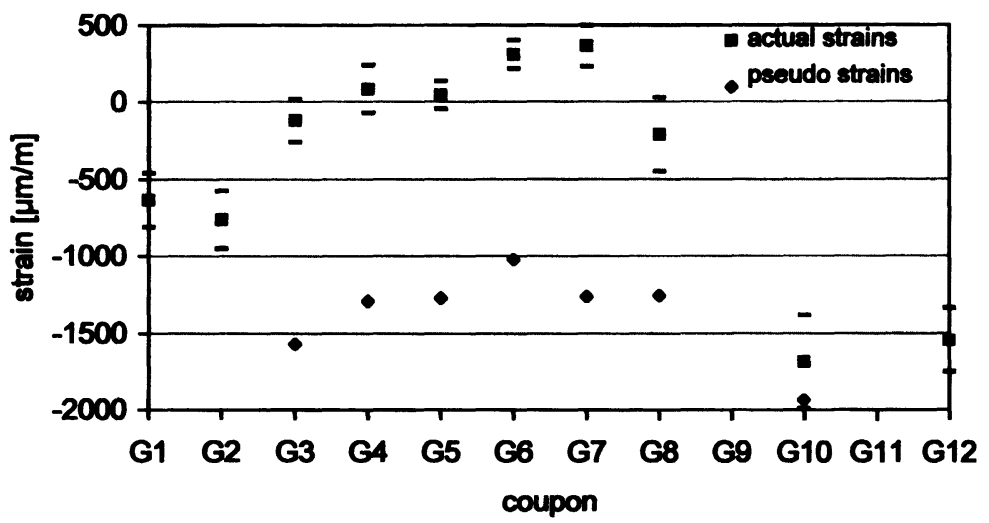

FIGURE 10 Residual strains measured along the weld transverse axis in the weld axial direction - At skipped locations the tests yielded insufficient neutron intensities due to texture.

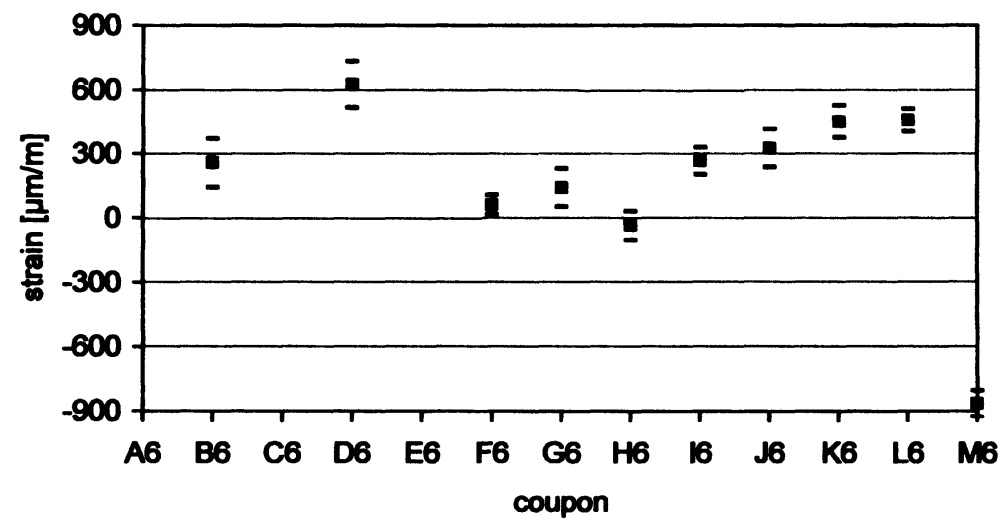

FIGURE 11 Residual strains measured along the weld axis of symmetry in the weld axial direction. 
and along its axis of symmetry. These results show, as those plotted in Fig. 10, that the weld material is exhibiting low tensile strains along the weld axis. Position M6 appears as an exception due to its position with respect to the geometry of the weld (see Fig. 5).

\section{HFR/HB4 Measurement Campaign}

Due to extensive work on the upgrading of the HB4 diffractometer only a few results on the HFR campaign can be reported here. It should be stated that the possibility of wavelength selection allows for the execution of strain measurements on the 111-, 002-, 022- and 113 -reflections within the vicinity of $2 \theta=90^{\circ}$. This has been tested on this specimen and will be applied in future investigations.

A short campaign in the axial direction on the 002-reflection has been performed. The applied wavelength of $2.572 \AA$ yielded a scattering angle of $60.7^{\circ}$. The sampling volume used was $3 \times 3 \times 4 \mathrm{~mm}^{3}$.

To avoid confusion two findings are presented in Tables III and IV, which compare very well with the respective findings of the CRNLcampaign. In Table III the resulting scattering angles of the 002-reflection at locations C6 to G6 are listed. In both campaigns it was found that the variation of the scattering angle mostly remains within very small margins, not exceeding the level of fit uncertainty.

Table IV shows the fit uncertainties resulting at locations G2-G9 of the same measurement campaign, based on the 002-reflection, in the weld axial direction. The fit uncertainties for G2-G6 are quite low. For locations G8 and G9 this error is consistently much higher for both

TABLE III Measured $2 \theta$ at locations C6 to G6

\begin{tabular}{lllllll}
\hline Location & & $C 6$ & D6 & E6 & $F 6$ & G6 \\
\hline HFR & 002-axial & 60.648 & 60.654 & 60.647 & 60.653 & 60.654 \\
CRNL & 002-axial & 50.41 & 50.391 & & 50.401 & 50.399 \\
\hline
\end{tabular}

TABLE IV Fit uncertainties of tests in axial direction on the 002-reflection at locations G2-G9

\begin{tabular}{lcccccccc}
\hline Location & $G 2$ & $G 3$ & $G 4$ & $G 5$ & $G 6$ & $G 7$ & $G 8$ & $G 9$ \\
\hline HFR & 0.007 & 0.004 & 0.004 & 0.007 & 0.005 & & 0.018 & 0.034 \\
CRNL & 0.008 & 0.007 & 0.008 & 0.003 & 0.003 & 0.006 & 0.012 & 0.047 \\
\hline
\end{tabular}


campaigns, which demonstrates that the specimen is textured. This texture renders low scattering intensity of the 002-reflection at locations G8 and G9, which prohibits the respective measurements.

Although at this point no strain measurement data can be presented, the results presented in Tables III and IV prove that it has been possible to repeat the same measurement campaign at the same specimen locations at HFR and CRNL. More HFR results will be published shortly (Youtsos and Ohms, 1997).

\section{CAST TRUCK MOTOR COMPONENT}

\section{Specimen Description}

Two specimens representing a cast truck motor component made from micro-alloyed steel were investigated (Ohms and Youtsos, 1996). One sample was as-received while the other was subjected to residual stress relief by heat treatment. The crystal structure of the material is body centred cubic. Figures 12 and 13 show the samples' geometry and the experimental setup.

Figure 12 shows the cross-section of the specimen and Fig. 13 its top view. The massive central part of the specimen with a diameter from 28 to $30 \mathrm{~mm}$ and a height of nearly $45 \mathrm{~mm}$ was the area of interest. This is because of the necessary post-fabrication mechanical work in this area, which is affected by high residual stresses induced by the fabrication process. At the centre of this area there is an insert of $15-\mathrm{mm}$ diameter, which is signed by a circular seam of this diameter to be seen on both ends of the specimen. It is understood that this manufacturing process contributes to the residual stress development as well. Thus the task of this test campaign is to determine the levels and patterns of residual stresses in this particular specimen region.

It was decided to perform a stress measurement campaign along a diameter at a distance of $2 \mathrm{~mm}$ from the sample's free surface as shown in Fig. 12. The selected locations are also shown in Fig. 12. These are at $0,3,6,8,10,12$ and $13-\mathrm{mm}$ distance from the axis of symmetry. A gauge volume of $3 \times 3 \times 2 \mathrm{~mm}^{3}$ was chosen for the radial and tangential measurement directions and of $2 \times 2 \times 3 \mathrm{~mm}^{3}$ for the longitudinal direction. These three mutually orthogonal directions were selected for 


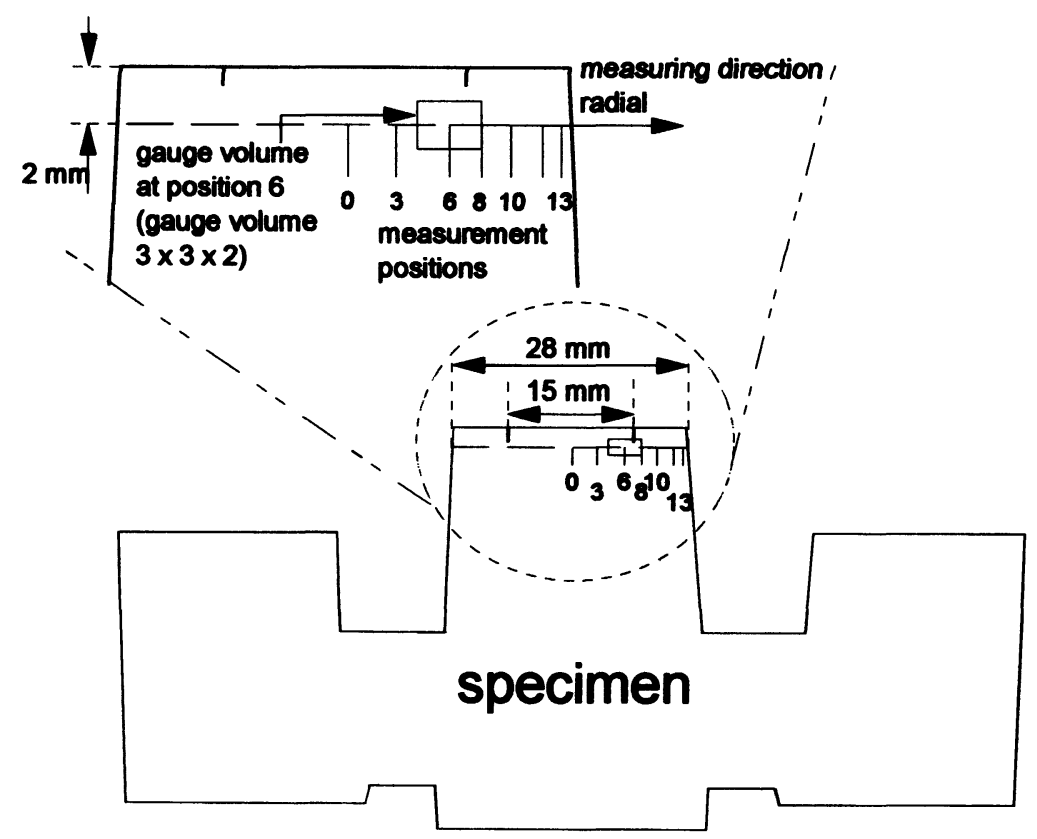

FIGURE 12 Cross-section of a truck motor part specimen indicating test positions and experimental setup details.

residual strain measurements since they are believed to be the principal axes of deformation.

\section{Residual Stress Measurements}

Figures 12 and 13 give a rough overview of the locations (gauge volumes) at which residual stress measurements were performed. Gauge volumes are defined by the intersection of the incoming and scattered beams. The primary and secondary diaphragms determine their size. The width of both diaphragms was set at $3 \mathrm{~mm}$ and the vertical opening of the primary was $2 \mathrm{~mm}$. This resulted in a gauge volume of $3 \times 3 \times 2 \mathrm{~mm}^{3}$ for the measurements in radial and tangential direction. For measuring in the longitudinal direction a gauge volume of $2 \times 2 \times 3 \mathrm{~mm}^{3}$ was used. As explained earlier measurements were made along a diametric line $2 \mathrm{~mm}$ below the specimen surface. On both sides of the specimen axis of symmetry measurements were made at a distance 


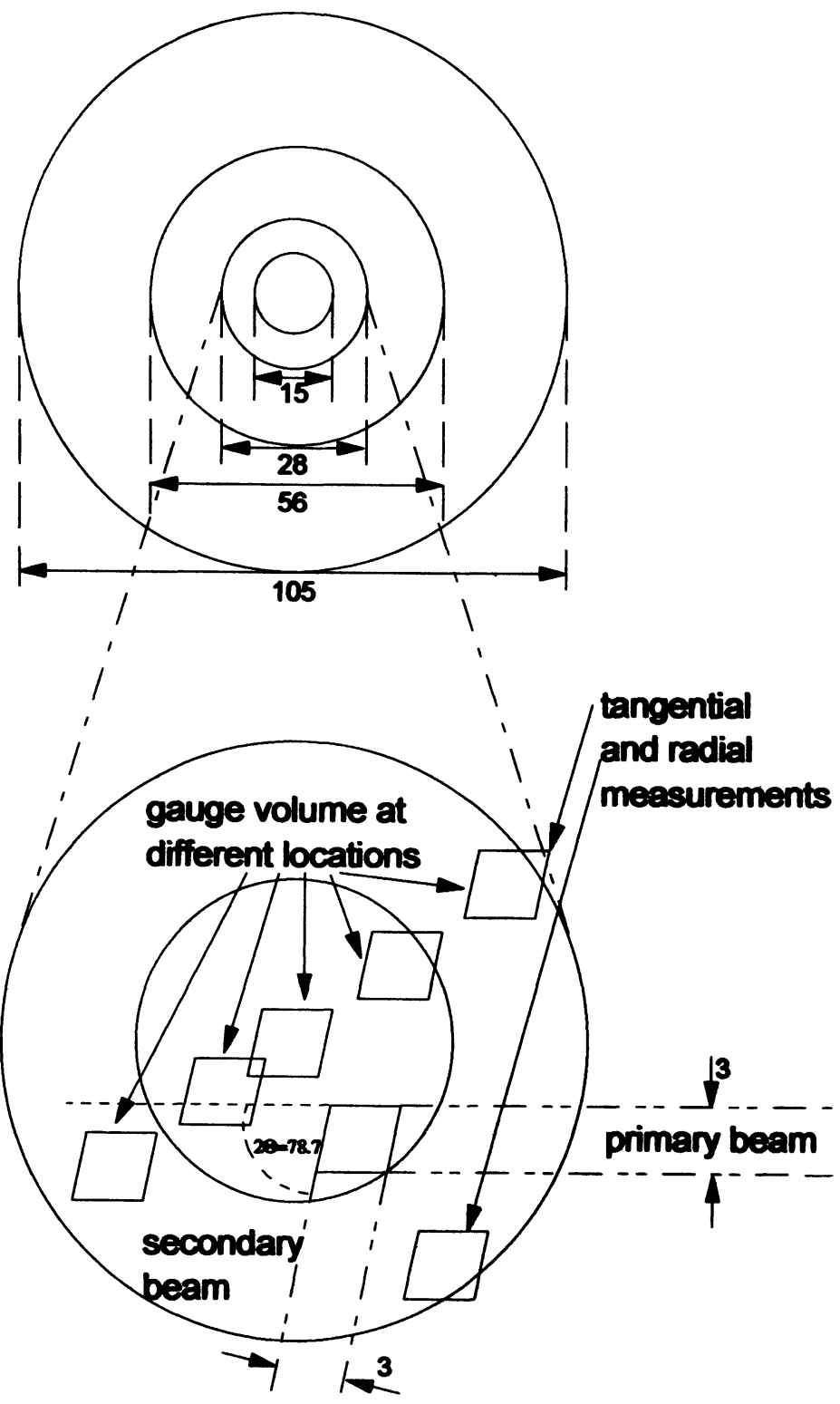

FIGURE 13 Specimen dimensions and gauge volume locations for radial and hoop strain measurements. 
of $0,3,6,8,10,12$ and $13 \mathrm{~mm}$. Since the measurements at $13-\mathrm{mm}$ distance are surely affected by surface effects they were not taken into account in the data evaluation. It was made sure, by rotating the sample properly, that for all testing directions measurements were performed at the same locations. Measurements duration varied by as much as one order of magnitude due to significant variations in the neutron beam path length within the specimen material. Several measurements had to be repeated for statistical reasons.

\section{Results and Concluding Remarks}

Figures 14-16 show the residual stresses measured in the as-received specimen based on a reference lattice parameter obtained from near surface measurements performed within the heat-treated specimen in the longitudinal direction and in a similar manner as described above in the case of the as-received specimen (see Table V). The plotted data show that all residual stresses, at a depth of $2 \mathrm{~mm}$ below the specimen top surface, are rather low and, mostly, in the range of $\pm 100 \mathrm{MPa}$ while their uncertainty lies in the range of $\pm 45 \mathrm{MPa}$. Table $\mathrm{V}$ also shows that the heat-treated specimen is indeed stress relieved at $2 \mathrm{~mm}$ below the specimen surface.

Additional measurements were performed on both specimens deeper below their top surface only in the longitudinal direction. Such

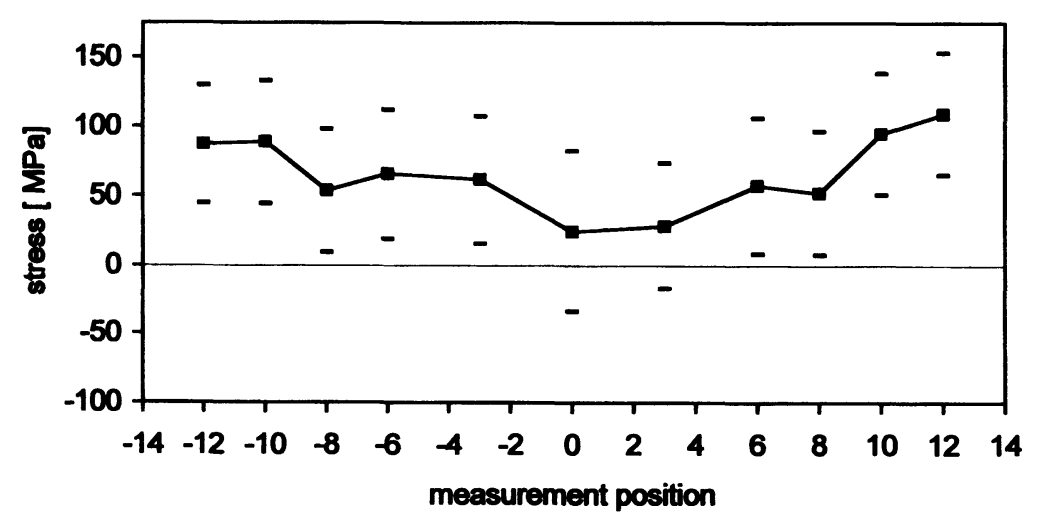

FIGURE 14 Radial residual stresses measured in as-received specimen - truck motor part. 


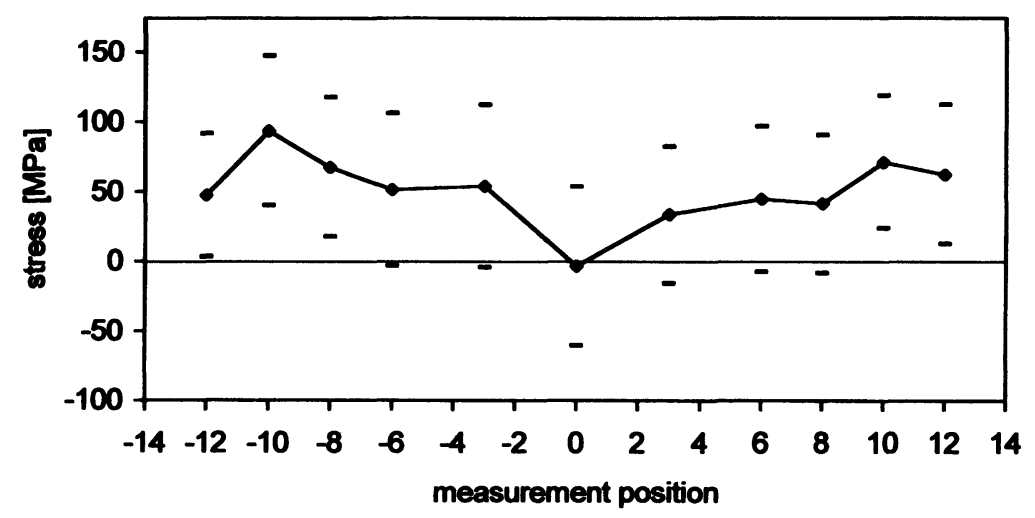

FIGURE 15 Hoop residual stresses measured in as-received specimen - truck motor part.

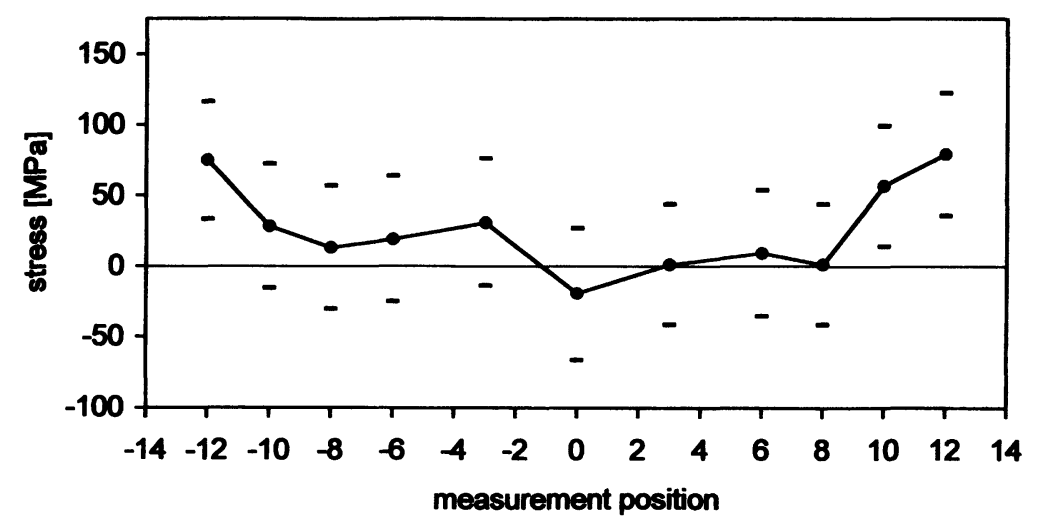

FIGURE 16 Longitudinal residual stresses measured in as-received specimen - truck motor part.

measurements were made at depth values of $4,6,10,12$ and $15 \mathrm{~mm}$ and at the axis of symmetry, and at $\pm 10 \mathrm{~mm}$ away from that axis. Based on our findings the following conclusions can be drawn. The longitudinal, tensile, strains increase sharply with depth increase and within the same depth they vary substantially along the radius. For instance, for the as-received specimen, at $15 \mathrm{~mm}$ depth, the difference in longitudinal strain values between two locations, i.e., at the axis of symmetry and at $10 \mathrm{~mm}$ from it, was found to be $+1250 \times 10^{-6} \pm 280 \times 10^{-6}$. For the 
TABLE $V$ Diffraction angle measured in the as-received and heat-treated truck motor part specimens in the longitudinal direction

\begin{tabular}{|c|c|c|c|c|c|}
\hline \multirow[t]{2}{*}{$\begin{array}{l}\text { Distance from } \\
\text { free surface (mm) }\end{array}$} & \multirow[t]{2}{*}{$\begin{array}{l}\text { Distance from axis } \\
\text { of symmetry }(\mathrm{mm})\end{array}$} & \multicolumn{2}{|c|}{$\begin{array}{l}\text { As-received } \\
\text { specimen }\end{array}$} & \multicolumn{2}{|c|}{$\begin{array}{l}\text { Heat-treated } \\
\text { specimen }\end{array}$} \\
\hline & & $2 \theta$ & $\Delta 2 \theta$ & $2 \theta$ & $\Delta 2 \theta$ \\
\hline 2 & -12 & 78.7351 & 0.0021 & 78.7478 & 0.002 \\
\hline 2 & -10 & 78.7637 & 0.0029 & 78.7515 & 0.0021 \\
\hline 2 & -6 & 78.7588 & 0.0027 & 78.7538 & 0.0028 \\
\hline 2 & -4 & 78.7534 & 0.0027 & 78.7512 & 0.0021 \\
\hline 2 & 0 & 78.7634 & 0.0023 & 78.751 & 0.0023 \\
\hline 15 & -10 & & & 78.6245 & 0.0023 \\
\hline 15 & 0 & & & 78.5717 & 0.004 \\
\hline
\end{tabular}

thermally treated specimen this difference is reduced to about one half of the above value, however the absolute values for these strains remain very high as Table $\mathrm{V}$ clearly shows. Thus it is concluded that the heat treatment process employed is not adequate for the effective residual stress relief deep within the specimen.

\section{CONCLUSIONS}

The performance of the HB4 and HB5 neutron diffraction facilities at JRC-Petten for residual stress investigation in crystalline materials has been established. Furthermore the efficiency of an upgrading campaign concerning the HB4 has been demonstrated. Concerning investigation of residual stress in structural components two major experimental campaigns have been described. The first, based on the recently upgraded HB4 instrument, has shown that mapping of residual strainstress tensors in and around a weld of thick piping is feasible. This, in our opinion, is a very important finding as neutron diffraction is the only method that can yield reliable quantitative data essential for the life assessment of structural systems of power and petrochemical plants. The second, based on the HB5 instrument, has shown that it is feasible to measure strain-stress accurately within a truck motor part and to evaluate the efficiency of a post-production stress relief process. A further enhancement of the HB4 facility is underway and its objective is to allow for efficient investigation of residual stresses in large structural components. 


\section{Acknowledgements}

Finally, we are grateful to Dr. Thomas Holden and his group at CRNL, Canada, for the significant support they have extended to us concerning the performance of the test campaign on the weld specimen at the Chalk River facility.

\section{References}

Brand, P.C. (1991). Stress measurements by means of neutron diffraction. ECN Report \# ECN-R-91-006, Petten, Holland.

Ezeilo, A.N. and Webster, G.A. (1993). Residual stress measurements in shot peened material using HB4 at HFR Petten. Internal Report. Department of Mechanical Engineering, Imperial College, London.

Frikkee, E. (1990). Neutron-beam facilities at Petten. Neutron News, 1(4), 10-15.

Holden, T.M., Robinsons, R.R., MacEwen, S.R., Flower, E.C., Bourke, M.A. and Goldstone, J.A. (1992). Measurement of residual and applied stress using neutron diffraction. In NATO ASI Series E, Vol. 26, eds. M.T. Hutchings and A.D. Krawitz, pp. 93-96. Dordrecht: Kluwer.

Holden, T.M. (1996). Residual stress measurements in austenitic steel welds by neutron diffraction. In Minutes of 2nd meeting of VAMAS TWA 20: Residual Stress, Chalk River, Canada.

Ohms, C. and Youtsos, A.G. (1996). Evaluation of residual stresses in a cast steel truck motor component. IAM Special Report, Petten.

Ohms, C. and Youtsos, A.G. (1997). Advances in residual stress investigations by neutron diffraction at HFR-Petten. 5th International Conference on Residual Stresses, Poster presentation, Linköping, Sweden.

Ohms, C. and Timke, Th. (1996a). Installation and acceptance tests of a 32 wire-detector at HB4/HFR. Project Progress Report, IAM-Petten.

Ohms, C. and Timke, Th. (1996b). HB4 instrumental resolution dependence on plane selection of the PG double momochromator. Project Progress Report, IAM-Petten.

Schroeder, J. and Youtsos, A.G. (1994). Measurement of localized stress fields by neutron scattering, Project Progress Report, IAM-Petten.

Winholtz, R.A. and Krawitz, A.D. (1995). Depth probing of stress tensors using neutron diffraction. Metallurgical Transactions, 26A, 1287-1295.

Youtsos, A.G. and Ohms, C. (1997). Residual stress measurements by neutron diffraction at JRC. In Proceedings of the 1st Hellenic Congress on Composite Materials and Structures, Vol. 1, eds. E.E. Gdoutos and S.A. Paipetis, pp. 321-349. Xanthi, Greece: University of Xanthi.

Youtsos, A.G., Ohms, C. and Timke, Th. (1997). Residual stress investigations by neutron diffraction at JRC-Petten. Physica B: Physics of Condensed Matter, 234-236, 959-961.

Youtsos, A.G. and Schroeder, J. (1994). Residual stress measurements in a ceramic coating/metal substrate specimen by neutron scattering. IAM Report on Special Activities. Petten.

Youtsos, A.G., Schroeder, J. and Timke, Th. (1995). Residual stress investigation near material interfaces by neutron diffraction at the JRC-Petten. In High Technology Composites in Modern Applications, eds. S.A. Paipetis and A.G. Youtsos, pp. 374-390. Patras, Greece: University of Patras.

Youtsos, A.G., Timke, Th., Kiriakopoulos, M. and Ceccone, G. (1994). Residual stress measurements in ceramic/metal joints by neutron scattering. IAM Report on Special Activities, No. P/A1/94/6. 